In the frrst case-an only eye, nearly blind-I believe I merely reinjected the fluid under the retina, as the detachment was very complete. In the second case I attempted to penetrate the retina through the vitreous, and succeeded, but the fluid was very dark in colour, and much vitreous opacity resulted. The third case was apparently quite successful, as the retina seemed in place after two weeks, and the vitreous was fairly clear. In this case, as in Mrs. J's, the subretinal fluid was very pale and when mixed with the saline in the syringe was almost colourless. Unfortunately, the patient had to leave and never kept his promise to return.

As regards the operation: if the sclerotic is well exposed and bleeding has been stopped, there is not much difficulty in passing a needle through a puncture in the sclerotic. A very efficient all glass syringe is essential, and I think a little sterile vaseline on the piston is useful as preventing it from slipping back and aspirating air before it is inserted. I started with about five minims of normal saline in the syringe and injected this with what one removed from beneath the retina until there was a distinct sense of tension. I have never been able to follow the needle inside the eyeball by using a mirror, but possibly efficient help might enable one to avoid the wrinkling of the cornea which is the main difficulty. The needle can be introduced till it touches the sclera and one should then be well under the retina. One has, however, less assurance that while withdrawing it the retina does not follow, and cause one to reinject the fluid into the subretinal space again. The idea which prompted one to try the method was of course that the fluid, if clear, was an organic fluid, and would possibly set up little irritation in the vitreous, and be more permanent than saline alone. I should, however, avoid in future making use of darkly tinted fluid, and my impression is that where one meets with this that the fate of the eye is certain blindness. Two successes out of four cases, none of which was promising, seems to show that the method is likely to be useful, and if it has any merit it may be worth recording that it was not done first in Germany.

\title{
ACCOMMODATIVE FAILURE IN MALARIA AND INFLUENZA
}

BY

\author{
D. J. WH:OOB, \\ CAPE TOWN, SOUTH AFRICA.
}

WE are all familiar with the ocular paralysis of diphtheria, with the temporary ciliary weakness of nursing women, and with the premature presbyopia of cases of elementary toxaemia, but within 
the last two years I have been brought in contact with numbers of cases of malaria from what was then German East Africa, and with a devastating epidemic of influenza, both of which have shewn me that a marked cyclo-paresis may occur in these two diseases.

In the malaria cases there were beside the complaint of headache, two ocular troubles, inability to stand sunlight and inability to read. These complaints were very constant in the cases of malaria sent back from East Africa. After a bad attack the tenderness of the eyes to light lasted, as a rule, for about a week, but the difficulty in reading persisted longer, a month or so if no second attack occurred to keep it going. Neutral tint glasses and an allowance for reading of a diopter or sometimes more were needed in a large number of cases where the men were well enough to go about freely.

In October, last year, South Africa was visited by influenza of virulent type, the death rolls in Kimberley and Cape Town being about 4,000 and 9,000 respectively.

After the disease had passed I began to get numbers of cases where patients were unable to read, though they were quite able to return to work. Some cases showed such complete cyclo-paresis that I was obliged to enquire carefully to assure myself that they were not post-diphtheritic. For example, I saw a girl of twenty seven who complained that her sight had been failing for nine days and had got so bad that on the morning of her visit she could not find her hairpins on her dressing table. She had had influenza with pneumonic complications a month before, and her accommodation was so poor that she could only read J. 10 at arm's length. She had only 0.5 of astigmatism and read 6/5. With the help of plus $2 \mathrm{D}$ sph. she read well.

In the same week, the beginning of December, I had a second case nearly identical : she was a cashier and was unable to see to add up her own columns of figures in the afternoon. Thereafter I saw scores of cases mostly not so bad, but with quite unmistakable accommodative failure demanding temporary help. The difficulty continued for many weeks, and recovery occurred slowly. In many of the cases there occurred at the same time the loss of hair with which every one is now familiar.

In malaria probably and in influenza certainly the failure of the ciliary muscle seemed to be out of all proportion to the amount of general illness and persisted after the patient felt quite well again.

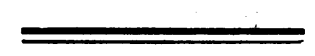

